УДК 577.11

\title{
Wound Dressings Made \\ of Biodegradable Natural Polymers \\ Polyhydroxyalkanoates (PHAs): \\ Production and Properties
}

\author{
Natalia V. Borovkova ${ }^{a}$, \\ Anatoly K. Evseeva, Yury V. Andreeva, \\ Dmitry B. Goncharov ${ }^{b}$ and Ekaterina I. Shishatskaya ${ }^{\text {b* }}$ \\ ${ }^{a} N . V$. Sklifosovsky Institute of Emergency Care \\ 3 Bolshaya Suharevskaya sq., Moscow, 129090, Russia \\ ${ }^{b}$ Institute of Biophysics of SB RAS \\ 50/50 Akademgorodok, Krasnoyarsk, 660036, Russia
}

Received 20.10.2015, received in revised form 25.11.2015, accepted 21.01.2016

\begin{abstract}
Increasing number of industrial and household injuries and burns lead to the necessity of research and development of new materials and resources for damaged skin regeneration. In this study results of experimental investigation of wound dressing made of natural degradable polyesters polyhydroxyalkanoates (PHAs) using electrospinning are presented. Studies on laboratory animals with model skin burns showed that the developed PHA membranes provide regeneration of the skin after 7 days and it is comparable with the control collagen dressings used in clinical practice. Developed nonwoven membranes may be used as the equivalent of collagen dressings in the treatment of II degree burns.
\end{abstract}

Keywords: polyhydroxyalkanoates, wound dressing, electrospinning, skin regeneration.

DOI: $10.17516 / 1997-1389-2015-9-1-88-97$.

(C) Siberian Federal University. All rights reserved

* Corresponding author E-mail address: shishatskaya@inbox.ru 


\section{Раневые покрытия}

\section{из разрушаемых природных полимеров полигидроксиалканоатов (ПГА): получение и свойства}

Н.В. Боровкова ${ }^{\text {a }}$ А.К. Евсеев ${ }^{\mathrm{a}}$, Ю.В. Андреев ${ }^{\text {a }}$, Д.Б. Гончаров ${ }^{0}$, Е.И. Шишацкая ${ }^{0}$ ${ }^{a}$ НИИ скорой помощи им. Н.В. Склифосовского Россия, 129090, Москва, пл. Большая Сухаревская, 3 ${ }^{6}$ Институт биофизики СО РАН Россия, 660036, Красноярск, Академгородок, 50/50

Рост количества производственных и бытовых травм и ожогов диктует необходимость поиска и разработки материалов и средств для восстановления повреждений кожных покровов. $B$ статье представлены результаты исследования экспериментальных раневых покрытий, сконструированных из разрушаемых природных полиэфиров полигидроксиалканоатов (ПГА) методом электростатического формования. Исследования на лабораторных животных с модельными ожогами кожных покровов показали, что разработанные мембраны из ПГА обеспечивают регенерацию кожи через 7 суток, что сопоставимо с контролем, в котором применяли принятую в клинической практике коллагеновую повязку. Разработанные нетканые мембраны могут быть использованы в качестве эквивалента коллагеновой повязки при лечении ожоговых ран II степени.

Ключевые слова: полигидроксиалканоаты, раневые покрытия, электростатическое формование, регенерачия кожных покровов.

\section{Введение}

Привлечение новых материалов для разработки эффективных средств восстановления повреждений кожных покровов является актуальной задачей реконструктивной медицины. Связано это с постоянным ростом количества дефектов кожи вследствие ожогов, травм и хирургических вмешательств. Круг хирургических и лечебных средств, применяемых для закрытия и восстановления дефектов кожных покровов, а также материалов и медикаментов, используемых для их изготовления, велик и насчитывает сотни наименований (Минченко, 2003; Абаев, 2006). Принци- пы и методы лечения кожных ран зависят от многих факторов: глубины и тяжести повреждения и фазы раневого процесса, локализации раны и степени инфицирования, сопутствующих заболеваний у пациента и принимаемых больным лекарств (Минченко, 2003; Абаев, 2006; Стручков с соавт., 1975). Главный принцип лечения - это очищение раны и создание оптимальных условий для регенерации.

Актуальное направление исследований это конструирование атравматичных раневых покрытий с использованием новых материалов. В основе создания неприлипающих повязок лежит принцип применения гидрофобно- 
го полимерного материала или формирование гидрофобного слоя на повязке, прилегающего к ране (Адамян с соавт., 2000). Рассасывающиеся покрытия в наибольшей степени отвечают медико-биологическим требованиям и могут быть полезны как на ранних стадиях лечения ран и ожогов, так и на более поздних стадиях. Разработка рассасывающихся полимерных покрытий с различными сроками биодеградации признана в настоящее время актуальным направлением в области создания эффективных покрытий на раны и ожоги. Это направление пока не получило распространения в силу ограниченности биоразрушаемых материалов, удовлетворяющих необходимым требованиям, предъявляемым к материалам для раневых повязок. Для совершенствования раневых повязок проводится активный поиск новых функциональных материалов и способов их переработки. Выполненный анализ литературы и результаты собственных исследований свидетельствуют о высоком потенциале материала из биоразрушаемых полиэфиров гидроксиалкановых кислот (полигидроксиалканоатов, ПГА), который не набухает и не гидролизуется в водной среде, резко не закисляет ткани при деградации, термостабилен, стерилизуется общепринятыми методами, обладает проницаемостью для паров воды и кислорода, биосовместим, не вызывает местного раздражающего и аллергического действия. Этот материал пригоден для переработки в гидрофобное, не прилипающее к ране покрытие в виде гибкой пленки и/или мембраны, образованной ультратонкими полимерными волокнами; прозрачен и обеспечивает возможность наблюдения за раной; позволяет вводить в изделия из него лекарственные препараты (Волова с соавт., 2014).

Цель настоящей работы - разработка

экспериментальных раневых повя- зок из сополимера 3-гидроксимасляной и 4-гидроксимасляной кислот, представителя семейства ПГА, и оценка эффективности их применения для реконструкции модельных дефектов кожных покровов после ожогов у лабораторных животных.

\section{Материалы и методы}

Использованы высокоочищенные образцы сополимера 3-гидроксимасляной и 4-гидроксимасляной кислот [П(3ГБ/4ГБ)] перспективного представителя семейства природных полимеров полигидроксиалканоатов, обеспечивающего получение прочных и эластичных изделий. Образцы П(3ГБ/4ГБ) синтезированы в Институте биофизики СО РАН в соответствии с Техническими условиями «ТУ 2200-002-385808452012 «Сополимер 3-гидроксимасляной и 4-гидроксивалериановой кислот». Материал сертифицирован в органах Федерального агентства по техническому регулированию и метрологии (№ POCC RU.AЯ08.H007905 (№ 1423201) и № РОCC RU.AЯ08.H007904 (№ 1423200). Зарегистрированная торговая марка материала «Биопластотан» (Регистрационное свидетельство № 315652, 2006).

Конструирование раневых повязок в виде нетканых мембран, образованных ультратонкими волокнами, выполнено по Техническим условиям 9393-008-38580845-2012 «Волокна хирургические стерильные «Биопластотан» методом электростатического формования растворов (ЭСФ) на автоматизированной установке Nanon 01A (MECC Inc., Япония).

Толщину мембран измеряли электронным цифровым микрометром «LEGIONER EDM-25-0.001» (Legioner, Китай); микроструктуру поверхности анализировали при помощи электронного микроскопа ТМ 3000 (Hitachi, Япония); предварительно образцы покрывали платиной (при 10 mA, 40 с) на 
установке для напыления Emitech K575X. Поверхностные характеристики образцов оценивали на приборе для измерения краевых углов DSA-25E (Krüss, Германия) с использованием программного обеспечения DSA-4 для Windows; измеряли краевые углы смачивания; из полученных значений методом Оунса-Вендта-Рабеля-Кьельбле рассчитывали свободную поверхностную энергию, ее дисперсную и полярную составляющие; физико-механические характеристики регистрировали с использованием универсальной разрывной машины Instron 5565 (Великобритания) с регистрацией Модуля Юнга (Е, МПа), абсолютной разрывной прочности ( $\sigma$, МПа) и удлинения при разрыве ( $\varepsilon, \%)$. Температуру плавления $\left(\mathrm{T}_{\text {плл }}\right)$ и температуру термической деградации образца ( $\left.\mathrm{T}_{\text {дегр }}\right)$, степень кристалличности $\left(\mathrm{C}_{\mathrm{x}}\right)$, средневесовую молекулярную массу $\left(\mathrm{M}_{\mathrm{B}}\right)$, среднечисловую молекулярную массу $\left(\mathrm{M}_{4}\right)$ и полидисперсность (Đ) определяли стандартными методами, описанными ранее (Volova et al., 2011). Шероховатость поверхности определяли с использованием атомно-силовой микроскопии (АСM) в полуконтактном режиме при помощи сканирующего зондового микроскопа SmartSPM"M; высоту неровностей профиля $\left(\mathrm{R}_{z}\right)$ вычисляли по 10 точкам как среднее арифметическое абсолютных значений отклонений высоты 5 самых высоких и 5 самых глубоких точек от средней линии профиля поверхности $2 \times 2$ мкм с помощью стандартных уравнений (ISO 468, 1982). Скорость паропроницаемости образцов (Water vapor transmission rate (WVTR)) определяли с использованием прибора Mocon Permatran-W 3/31 (Миннеаполис, Миннесота, США). Площадь образцов составляла $5 \mathrm{~cm}^{2}$. Образцы анализировали при $37,8{ }^{\circ} \mathrm{C}$. Значения WVTR регистрировались при достижении концентрации водяного пара устойчивого/равновесного состояния.
Полученные мембраны затаривали в упаковку Tyvek®Roll с помощью термоупаковочной машины (NS 1000, Германия) и стерилизовали плазмой $\mathrm{H}_{2} \mathrm{O}_{2}$ в медицинском стерилизаторе Sterrad NX (Johnson\&Johnson, США). Изделия сертифицированы в органах Федерального агентства по техническому регулированию и метрологии (сертификат № POCC. RU. ФЯ08.H07998 (№ 1570609).

Экспериментальные исследования проведены на 24 взрослых беспородных белых мышах весом 25-30 г. Мышей содержали на обычном рационе вивария. Моделирование ожога производили наркотизированным животным (внутрибрюшинно 2\%-м ксилазином в дозе 0,003 мл/мышь). На выбритый участок спины (3 см²) подшивали полихлорвиниловое (ПВХ) кольцо диаметром 12 мм для предотвращения контракции ожоговой раны. Нанесение ожога производили стальной печаткой диаметром 12 мм, которую нагревали до $100{ }^{\circ} \mathrm{C}$ в кипящей воде в течение 10 мин. Время экспозиции на ране составляло 8 с. Получали ожоговое поражение кожи II степени по классификации МКБ-10. После ожога рана становилась белого цвета, эпидермис плотно держался на ране, пузыри отсутствовали. Спустя 5-10 мин кожа начинала розоветь, эпидермис при помощи марлевого тампона отслаивали от подлежащей дермы, которая к тому времени становилась красно-бордового цвета. Животные были разделены на две группы, по 12 в каждой. В экспериментальной группе кожный дефект закрывали полимерной мембраной и укрывали сухой стерильной марлевой повязкой, которую фиксировали к пластиковому кольцу одиночными швами. В контроле использовали лиофилизированную коллагеновую повязку, предварительно размоченную физиологическим раствором, накрывали сухой стерильной марлевой повязкой, которую фиксировали к пластиковому кольцу одиночными швами. 
После нанесения ожога каждая мышь находилась в отдельной клетке. Длительность наблюдений составила 7 суток. Вывод животных из эксперимента проводили на 3-, 7-е сутки эксперимента по 6 особей методом дислокации шейных позвонков. Критериями оценки специфической активности раневых покрытий на модели ожоговой раны II степени площадью 2 \% поверхности тела были выраженность воспалительной реакции в ране и окружающих мягких тканях, скорость и полноценность восстановления кожного покрова. Воспалительную реакцию макроскопически оценивали по характеру раневого отделяемого, отеку и гиперемии окружающих тканей, при микроскопии обращали внимание на наличие и характер клеточной инфильтрации. Скорость и полноценность восстановления кожного покрова оценивали по степени эпителизации раны. Послойные фрагменты тканей из области раны с захватом краев удаляли и фиксировали в $10 \%$ м растворе формалина. После стандартной гистологической проводки и заливки в парафин готовили гистологические срезы, которые были окрашены гематоксилином и эозином. Степень коллагенообразования оценивали с помощью гистохимического окрашивания по Ван-Гизону.

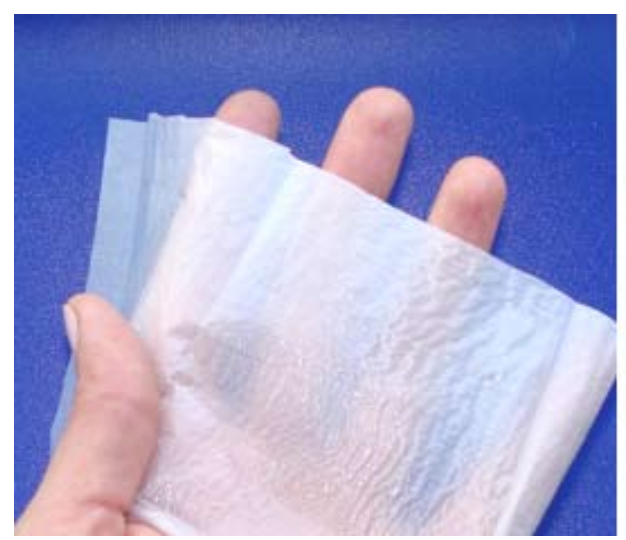

\section{Результаты и обсуждение}

Внешний вид и микроструктура раневых покрытий в виде нетканых мембран из сополимера П(ЗГБ/4ГБ) изображены на рис. 1. В табл. 1 и 2 представлены характеристики нетканых мембран.

Полученные гидрофобные нетканые мембраны по своим механическим характеристикам сопоставимы с характеристиками кожи (Ying et al., 2008), т.е. могут быть использованы в дальнейшем для разработки ее тканеинженерных эквивалентов. Показатели паропроницаемости у разработанных ЭСФ-мембран значительно превосходят этот показатель у синтетических пленочных материалов (полиэтилен, полипропилен, полиэтилентерифталат и др.).

При проведении экспериментов по оценке эффективности мембран на лабораторных животных с модельными ожогами кожных покровов все животные выжили. К третьим суткам признаков гнойных осложнений среди животных обеих групп не выявлено. При визуальном осмотре ран у животных как контрольной, так и опытной групп отмечали местные признаки воспаления: незначительную отёчность и гиперемию окружающих мягких тканей, чистое дно раны (рис. 2).

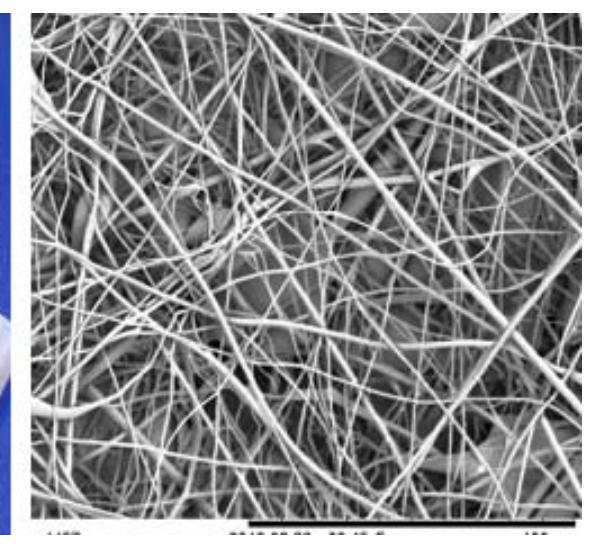

Рис. 1. Внешний вид и микроструктура (РЭМ-снимок) нетканых неориентированных мембран, образованных ультратонкими волокнами методом электростатического формования из П(3ГБ/4ГБ) 


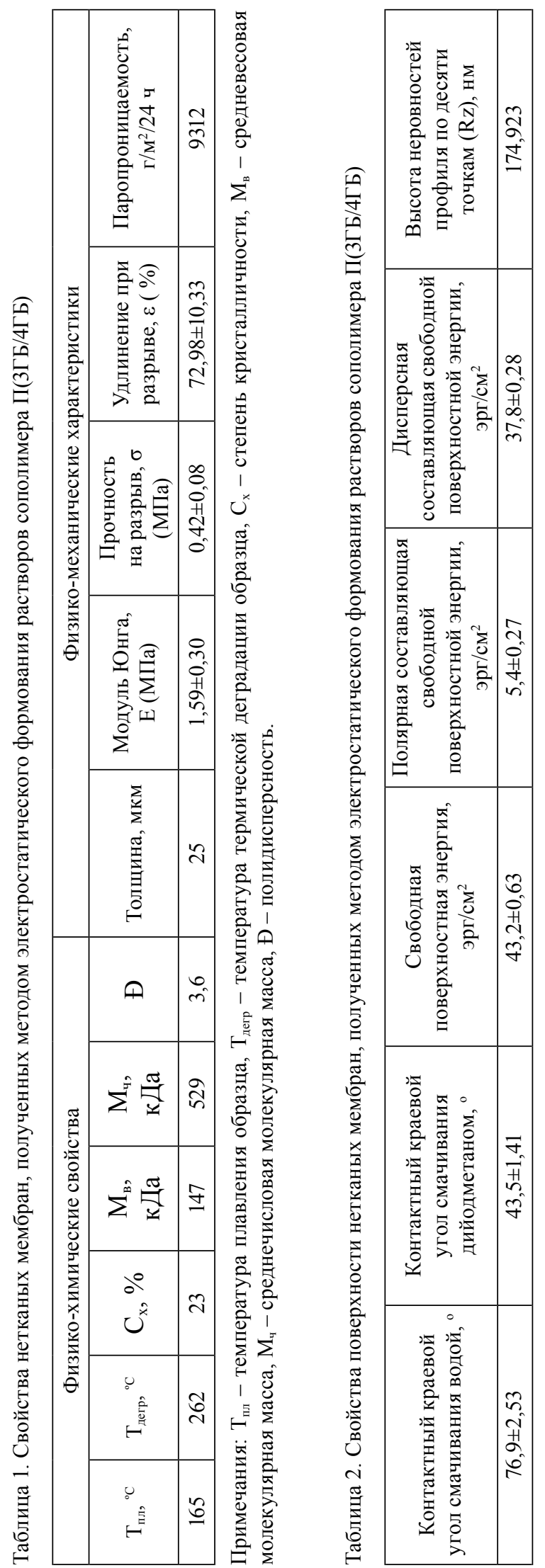





Рис. 2. Вид раны на 3-и сутки эксперимента в контроле под коллагеновой повязкой (а) и при использовании экспериментальной полимерной мембраны (б)

Через трое суток после наложения повязки гистологическая картина раневой поверхности в контроле (коллагеновая повязка) и в опыте (полимерная мембрана) была сходной (рис. 3).

В области раны полностью отсутствовал эпидермальный слой с базальной мембраной и сосочковый слой дермы, в сетчатом слое дермы наблюдалась отчетливая деформация. В обоих вариантах на большей площади раны клеточные компоненты дермы отсутствовали или были заметно повреждены, волосяные фолликулы отсутствовали или выявлялись в незначительном количестве вблизи границы с подкожно-жировой клетчаткой. Отмечена очень высокая уплотненность волокон межклеточного матрикса, сопровождающаяся нарушением нормальной архитектоники коллагеновых волокон и их структуры.

Интенсивность свечения коллагеновых волокон сетчатого слоя дермы в области раны (рис. 36,2$)$ составила в среднем $(63,7 \pm 1,0)$ футкандел при норме 45-60 фут-кандел, что указывает на химическое разрушение коллагена как в опыте, так и в контроле. Микроскопическая картина соответствовала ожоговой ране II степени. В обеих группах отмечена высо- кая инфильтрация раневой поверхности и прилегающих к ней областей кожи клетками воспаления (главным образом нейтрофилы и макрофаги), при этом такие клетки выявлялись не только в дерме, но и в подлежащих слоях - подкожно-жировой клетчатке, мышечном слое. Таким образом, в контроле и опыте отмечали морфологические признаки, характерные для фазы воспаления. Регенераторных процессов в эти сроки не выявлено.

К 7-м суткам у животных признаки гнойных осложнений отсутствовали. По сравнению с 3-ми сутками отмечено уменьшение отека и гиперемии. При удалении повязки на дне раны оставался блестящий белесый налет у животных контрольной группы (рис. $4 a$ ) и матовый белесый налет у животных экспериментальной группы (рис. 4б).

Через 7 суток после наложения повязки в области раневой поверхности в контроле и в опыте отмечена нормализация структуры сетчатого слоя дермы и активное формирование сосочкового слоя дермы, сопровождающееся активным формированием дериватов кожи (рис. 5).

Грануляционная ткань в области раны практически отсутствовала - характерные 

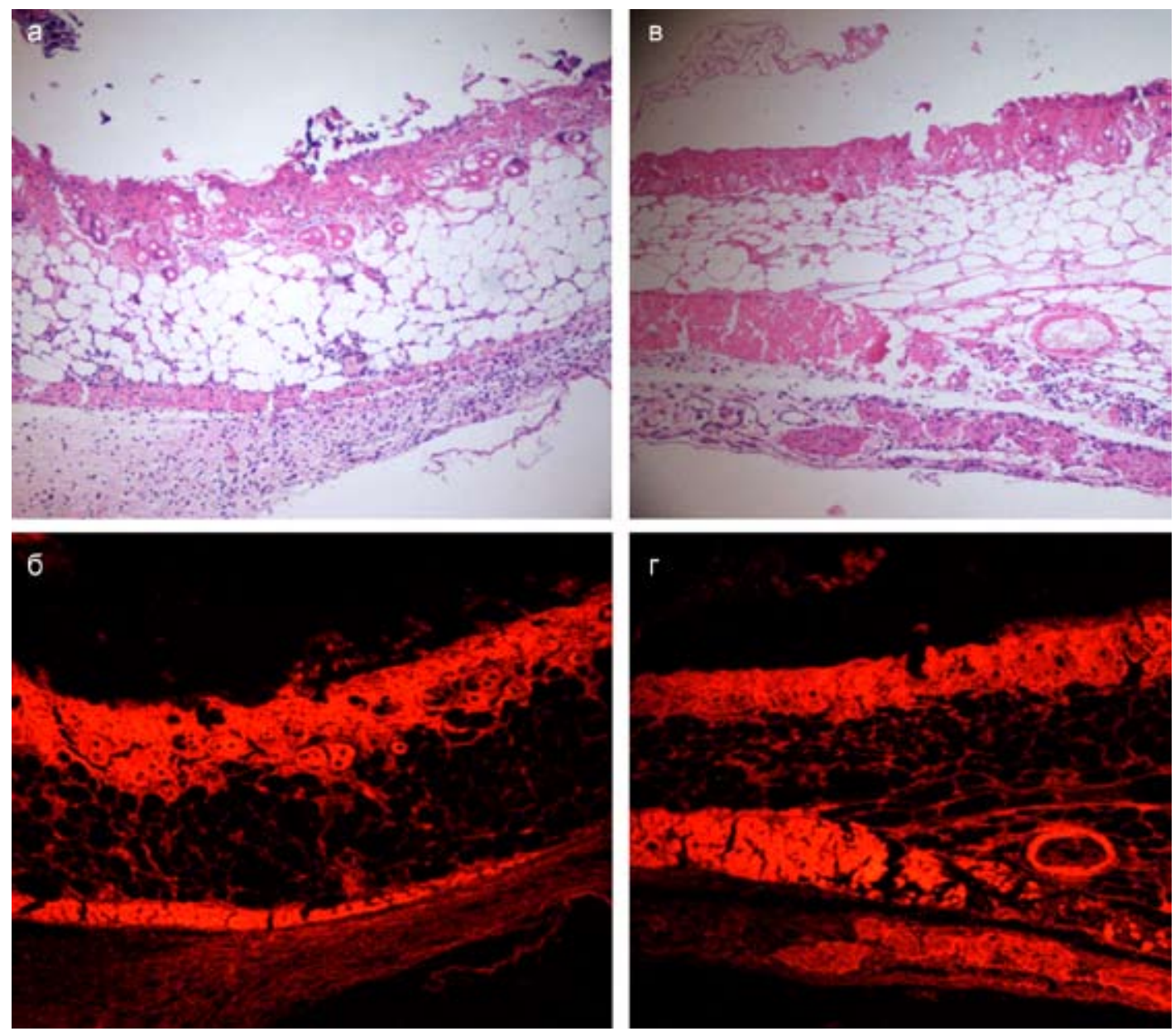

Рис. 3. Макроскопическая картина раны на 3-и сутки при применении коллагеновой повязки (контроль) $(\mathrm{a}$, б) и экспериментальной полимерной мембраны (в, г); увеличение х 100 . Верхний ряд - окраска гематоксилином и эозином; нижний ряд - аутофлуоресценция коллагеновых волокон
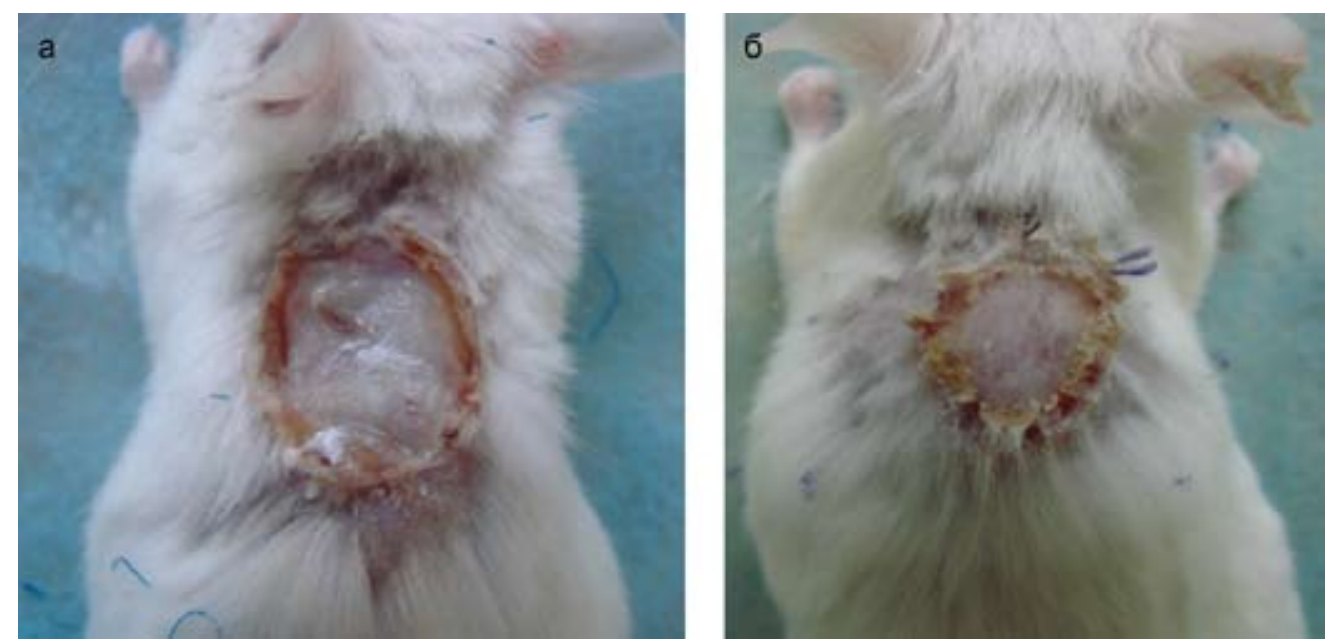

Рис. 4. Вид раны на 7-е сутки эксперимента в контроле под коллагеновой повязкой (а) и при использовании экспериментальной полимерной мембраны (б) 

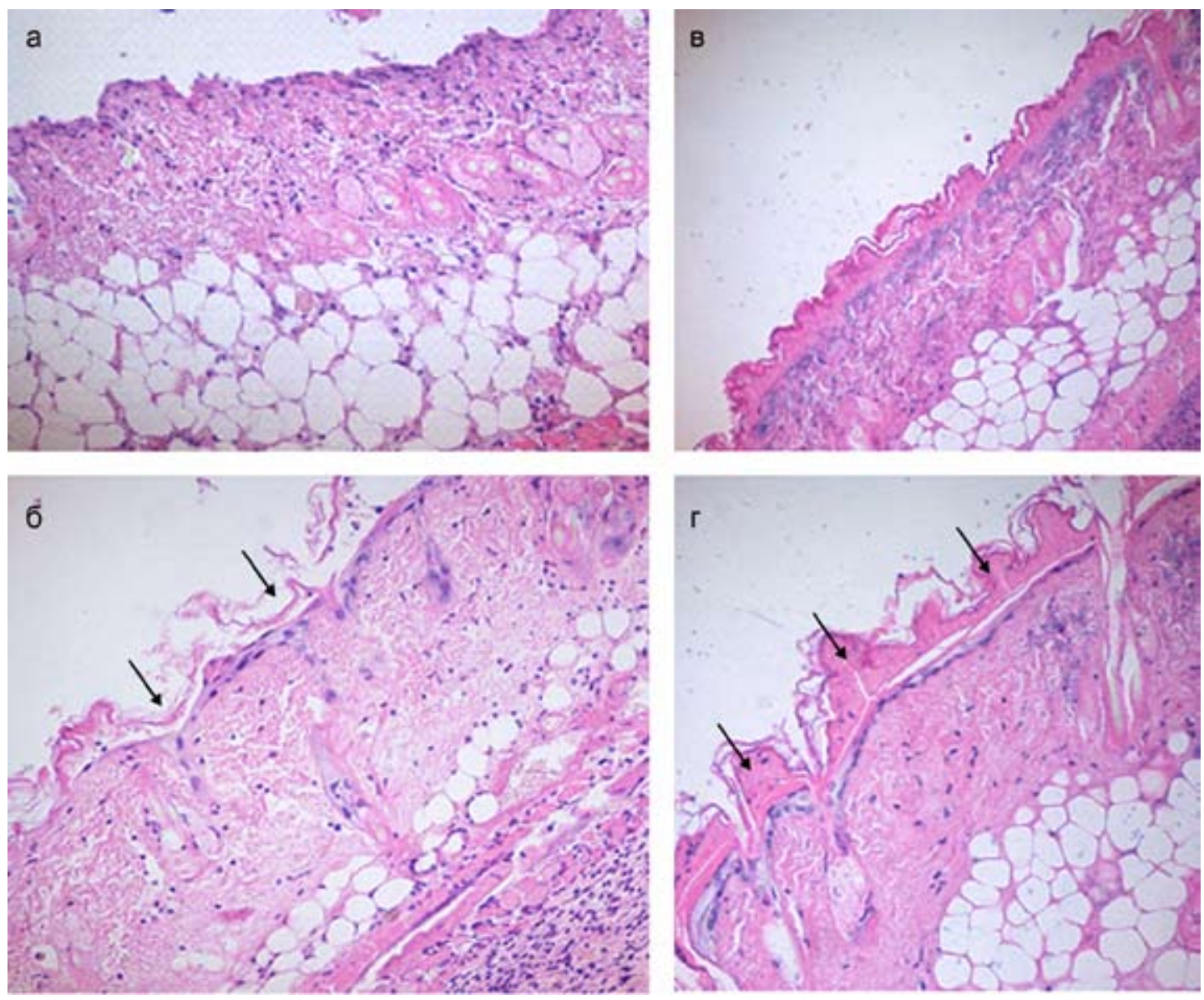

Рис. 5. Микроскопическая картина раны на 7-е сутки при применении коллагеновой повязки (контроль): дно раны (а) и области краевой эпителизации (б); при применении экспериментальной полимерной мембраны: дно раны (в) и области краевой эпителизации (г). Окраска гематоксилином и эозином; увеличение х 100. Стрелками показаны лейкоциты, фибробласты, макрофаги, кератиноциты

формирования из тесно собранных сосудов с мигрирующими из них фибробластами были выявлены в незначительном количестве у 1 мыши из 6 в контроле и полностью отсутствовали в опыте. Архитектоника волокон межклеточного матрикса дермы имела такое же строение, что и в неповрежденных участках кожи; интенсивность свечения коллагеновых волокон дермы в области раны составила в среднем $(50,9 \pm 1,0)$ фут-кандел, что также соответствует норме.

К 7-м суткам формирование дермы в области раны было в значительной степени завершено как в опыте, так и в контроле; отмечено невысокое содержание клеток воспаления, преимущественно макрофагов, распределение которых имело диффузный характер. Базальная мембрана и эпидермис в обоих случаях отсутствовали; вместе с тем отмечена краевая эпителизация раны у 2 мышей в контроле и у 3 мышей в опыте.

\section{Заключение}

Разработаны и охарактеризованы экспериментальные раневые покрытия в виде нетканых мембран, полученных методом электростатического формования растворов разрушаемого природного полимера 
П(ЗГБ/4ГБ). Применение разработанных экспериментальных мембран для закрытия кожных дефектов с модельными ожогами обеспечило через 7 суток регенерацию кожи, что сопоставимо с контролем в случае примене- ния принятой в клинической практике коллагеновой повязки. Разработанные нетканые мембраны могут быть использованы в качестве эквивалента коллагеновой повязки при лечении ожоговых ран II степени.

Работа выполнена за счет средств государственного задания на проведение фундаментальных исследований РАН (проект № гос. регистрации 01201351505).

\section{Список литературы}

Абаев Ю.К. (2006) Раны и раневая инфекция: Справочник хирурга. М., Феникс, 427 с. [Abaev Yu.K. (2006) Wounds and wound infection. Manual of surgeon. Moscow, Feniks, 427 p. (in Russian)]

Адамян А.А., Добыш С.В., Килимчук Л.Е. (2000) Биологически активные перевязочные средства в комплексном лечении гнойно-некротических ран: методические рекомендации. М., Медицина, 32 с. [Adamyan A.A., Dobish S.V., Kilimchuk L.E. (2000) Bioactive wound dressings in treatment of necrotic wounds: guidelines. Moscow, Medicine, 32 p. (in Russian)]

Волова Т.Г., Винник Ю.С., Шишацкая Е.И., Маркелова Н.М. (2014) Биомедицинский потенциал разрушаемых полигидроксиалканоатов: экспериментально-клинические исследования. Красноярск, Издательство BEPCO, 330 с. [Volova T.G., Vinnik Yu.S., Shishatskaya E.I., Markelova N.M. (2014) Biomedical potential of degradable polyhydroxyalkanoates: Experimental and clinical studies. Krasnoyarsk, VERSO, 330 p. (in Russian)]

Минченко А.Н. (2003) Раны. Лечение и профилактика осложнений. СПб., СпецЛит, 216 c. [Minchenko A.N. (2003) Wounds. Treatment and prevention of complications. Sankt Petersburg, SpecLit, 216 p. (in Russian)]

Стручков В.И., Григорян А.В., Гостищев В.К. (1975) Гнойная рана. М., Медицина, 309 с. [Struchkov V.I., Grigoryan A.V., Gostischev V.K. (1975) Purulent wound. Moscow, Medicine, 309 p. (in Russian)]

Торговая марка «БИОПЛАСТОТАН. Регистрационное свидетельство № 315652 Федерального института патентной экспертизы по заявке № 2006703271/50, приоритет от 15.02.2006. Классы МКТУ: 01, 05, 10. [Brand "BIOPLASTOTAN". The registration certificate number 315652 of Federal Institute of Patent Examination of application № 2006703271/50, a priority from 15.02.2006. The classes of the Nice Classification: 01, 05, 10 (in Russian)]

Volova T.G., Zhila N.O., Kalacheva G.S., Sokolenko V.A., Sinski E.J. (2011) Synthesis of 3-hydroxybutyrate-co-4-hydroxybutyrate copolymers by hydrogen oxidizing bacteria. Applied Biochemistry and Microbiology, 47 (5), 494-499

Ying T.H., Ishii D., Mahara A., Murakami S., Yamaoka T., Sudesh K., Samian R., Fujita M., Maeda M., Iwata T. (2008) Scaffolds from electrospun polyhydroxyalkanoate copolimers: fabrication, characterization, bioabsorbtion and tissue response. Biomaterials, 29: 1307-1317 